\title{
Biotransformation of Digitoxigenin by Fusarium Ciliatum
}

\author{
Rodrigo M. Pádua ${ }^{a}$, Alaíde B. Oliveira ${ }^{a}$,José D. Souza Filho ${ }^{b}$, Géssy J. Vieira ${ }^{b}$,Jacqueline A. \\ Takahashi ${ }^{b}$ and Fernão C. Braga ${ }^{*, a}$
}

${ }^{a}$ Faculdade de Farmácia and ${ }^{b}$ Departamento de Química, Universidade Federal de Minas Gerais, Av. Antônio Carlos, 6627, 31270-010 Belo Horizonte - MG, Brazil

\begin{abstract}
A biotransformação da digitoxigenina (1) por Fusarium ciliatum foi investigada. O cardenolídeo 1 foi obtido a partir da hidrólise ácida da digitoxina e a reação também forneceu os produtos secundários $\Delta^{14-15}$-digitoxigenina (2) e $\Delta^{8-14}$-digitoxigenina (3). A reação de biotransformação foi realizada em um período de 5 dias e três produtos foram isolados e identificados a partir de análises espectrométricas: digoxigenina (4), digoxigenona (5) e digitoxigenona (6). A obtenção dos dois últimos cardenolídeos nas condições empregadas é inédita. A investigação da cinética da reação de biotransformação indicou 6 como o primeiro produto a ser formado, seguido dos derivados hidroxilados $\mathbf{4}$ e $\mathbf{5}$, sugerindo o envolvimento de enzima distintas na hiroxilação em $12 \beta$ e na oxidação em C-3 da digitoxigenina (1). A reação de biotransformação também foi realizada com a digitoxina, mas $F$. ciliatum se mostrou incapaz de promover sua hidroxilação.

The biotransformation of digitoxigenin (1) by Fusarium ciliatum was investigated. The cardenolide 1 was obtained by the acid hydrolysis of digitoxin and the reaction also afforded two side products, identified as $\Delta^{14-15}$-digitoxigenin (2) and $\Delta^{8-14}$-digitoxigenin (3) by spectroscopic analysis. The biotransformation reaction was carried out in a 5 days process and three products were isolated and had their structures elucidated as digoxigenin (4), digoxigenone (5) and digitoxigenone (6). The investigation of the biotransformation kinetics disclosed $\mathbf{6}$ as the first derivative to be formed, followed by the more polar hydroxylated products $\mathbf{4}$ and $\mathbf{5}$, suggesting the involvement of different enzymes in $12 \beta$ hydroxylation and C-3 oxydation of digitoxigenin (1). The production of 5 and $\mathbf{6}$ under the employed conditions has never been reported. The biotransformation reaction was also undertaken with digitoxin, but $F$. ciliatum has been unable to promote its hydroxylation.
\end{abstract}

Keywords: digitoxigenin, Fusarium ciliatum, digoxigenin, digoxigenone, digitoxigenone

\section{Introduction}

Digoxin (Figure 1), a Digitalis cardenolide, is still the drug of choice for the treatment of congestive heart failure, acting as a selective inhibitor of the $\mathrm{Na}^{+}, \mathrm{K}^{+}$ATPase enzyme. The Digitalis cardenolides are divided into 6 series, based on their genin part, termed A through F. Glycosides of the A series, like lanatoside A, are the most abundant ones, whereas C-type compounds, such as lanatoside $\mathrm{C}$ and digoxin, are those clinically used. ${ }^{1}$

The steroid nucleus of the $\mathrm{C}$ glycosides differ from the A glycosides only at the $\mathrm{C}-12 \beta$ position, the former bearing a hydroxyl group. Lanatoside $\mathrm{C}$ and its derivative digoxin are industrially obtained from the leaves of Digitalis lanata and lanatoside A constitutes a side product. Therefore, it is

\footnotetext{
*e-mail: fernao@netuno.lcc.ufmg.br
}

of interest to find out a process to convert the A-type cardenolides into the corresponding C-type compounds.

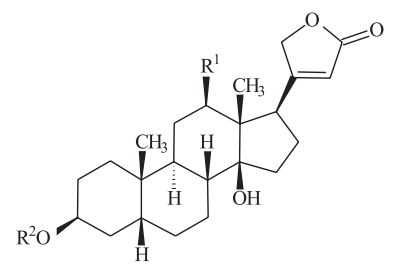

\begin{tabular}{lclc}
\hline \hline Cardenolide & Series & \multicolumn{1}{c}{$\mathbf{R}^{\mathbf{2}}$} & $\mathbf{R}^{\mathbf{1}}$ \\
\hline Lanatoside A & A & Glc- $\beta 1-4-\alpha-$ AcDox- $\beta 1-4-D o x-\beta 1-4-D o x-\beta 1-$ & $\mathrm{H}$ \\
Digitoxin & A & Dox- $\beta 1-4-D o x-\beta 1-4-D o x-\beta 1-$ & $\mathrm{H}$ \\
Lanatoside C & C & Glc- $\beta 1-4-\alpha-$ AcDox- $\beta 1-4-D o x-\beta 1-4-D o x-\beta 1-$ & $\mathrm{OH}$ \\
Digoxin & C & Dox- $\beta 1-4-D o x-\beta 1-4-D o x-\beta 1-$ & $\mathrm{OH}$ \\
\hline \hline
\end{tabular}

Glc, glucose; Dox, digitoxose; $\alpha$-AcDox, $\alpha$-acetyldigitoxose

Figure 1. Chemical structures of cardenolides. 
Several plant cell cultures have been investigated as a synthetic tool to obtain derivatives of Digitalis cardenolides and the biotransformation of digitoxin into digoxin was successfully accomplished with $D$. lanata cells in a semi-continuous process. ${ }^{2}$

Filamentous fungi usually present rates of biomass growth higher than those of plant cell cultures, what turns out fungal transformations more feasible for large scale applications. ${ }^{3}$ The capacity of Fusarium lini and F. ciliatum to promote digitoxigenin hydroxylation at $12 \beta$-position has been demonstrated..$^{4-7}$ The second species also promoted oxidation of the $\mathrm{C}-3 \beta \mathrm{OH}$ and digoxigenone was obtained. ${ }^{6} F$. lini was also investigated for the biotransformation of digitoxin, without success, ${ }^{5}$ whereas no report was found on the transformation of this substrate by $F$. ciliatum. Since digitoxin bears a sugar chain at C-3, impairing the oxidation of this position, $F$. ciliatum seems to be a suitable candidate to transform digitoxin into digoxin. Therefore, the main goal of the present work was to study the biotransformation of digitoxigenin (1) by $F$. ciliatum and to carry out the reaction with digitoxin aiming at the production of digoxin.

\section{Materials and Methods}

\section{General}

${ }^{1} \mathrm{H}$ NMR, ${ }^{13} \mathrm{C}$ NMR, ${ }^{1} \mathrm{H}{ }^{1} \mathrm{H}$ COSY and HMQC spectra were recorded on a Bruker DRX-400 spectrometer $\left({ }^{1} \mathrm{H} 400\right.$ $\mathrm{MHz}$ and ${ }^{13} \mathrm{C} 100 \mathrm{MHz}$ ) using TMS as internal standard for both nuclei. Chemical shifts $(\delta)$ are given in ppm and $J$ couplings in Hertz $(\mathrm{Hz})$.

\section{Chemicals}

Acetonitrile chromatographic grade LiChrosolv and digitoxin were obtained from Merck (Germany). Water was purified using a Milli- $\mathrm{Q}^{50}$ purification system (Millipore, USA).

\section{Preparation and purification of cardenolides}

Digitoxin was purified on a Shimadzu HPLC system (Japan) composed of pump LC-8A, UV-Vis detector SPDGAV, controller system SCL-8A and integrator C-R4A. An ODS column $(250 \times 20 \mathrm{~mm}$ I.D. $)$ was employed (Shimadzu, Japan) at room temperature, eluted with $84 \%$ aqueous $\mathrm{CH}_{3} \mathrm{CN} / \mathrm{H}_{2} \mathrm{O}(7: 3)$, at a flow rate of $4.8 \mathrm{~mL} \mathrm{~min}^{-1}$ and $\mathrm{UV}_{220}$ detection. Aliquots of digitoxin $(40 \mathrm{mg})$ were dissolved in $\mathrm{MeOH}: \mathrm{CHCl}_{3}(9: 1 ; 1 \mathrm{~mL})$ for injection into the apparatus $\left(\mathrm{t}_{\mathrm{R}}\right.$ of digitoxin: $\left.24.8 \mathrm{~min}\right)$.

Digitoxigenin (1) was obtained by the acidic hydrolysis of digitoxin (Figure 2). A portion of digitoxin (750 mg) was dissolved in $\mathrm{MeOH}(250 \mathrm{~mL})$ under sonication, following addition of aqueous $1 \mathrm{~mol} \mathrm{~L}^{-1} \mathrm{HCl}(250 \mathrm{~mL})$. The solution was heated at $55^{\circ} \mathrm{C}$, for $35 \mathrm{~min}$, following extraction with $\mathrm{CHCl}_{3}(3 \times 500 \mathrm{~mL})$. The organic layer was neutralized with $3 \% \mathrm{NaHCO}_{3}$ aqueous solution and concentrated until residue $(295.7 \mathrm{mg})$. Portions of the residue $(20 \mathrm{mg}$ ) were dissolved in $\mathrm{MeOH}(1 \mathrm{~mL})$ for injection into HPLC equipment. Digitoxigenin (1) and the side products $\mathbf{2}$ and $\mathbf{3}$ were separated by preparative RP-HPLC, under the conditions previously described for digitoxin purification $\left(t_{\mathrm{R}}\right.$ of 1: $20.5 \mathrm{~min}, 236.4 \mathrm{mg}, 64 \%$ yield; 2: $46.6 \mathrm{~min}, 16.4 \mathrm{mg}$, 5\% yield; 3: $50.0 \mathrm{~min}, 6.4 \mathrm{mg}$, $2 \%$ yield).

\section{Biotransformation experiments}

Fusarium ciliatum (syn. Calonectria decora) CBS 21554 was obtained from Centralalbureau voor Schimmelcultures (CBS) (Utrecht, Holand). Seven days old cultures, grown in PDA medium, at room temperature, were employed for the experiments.

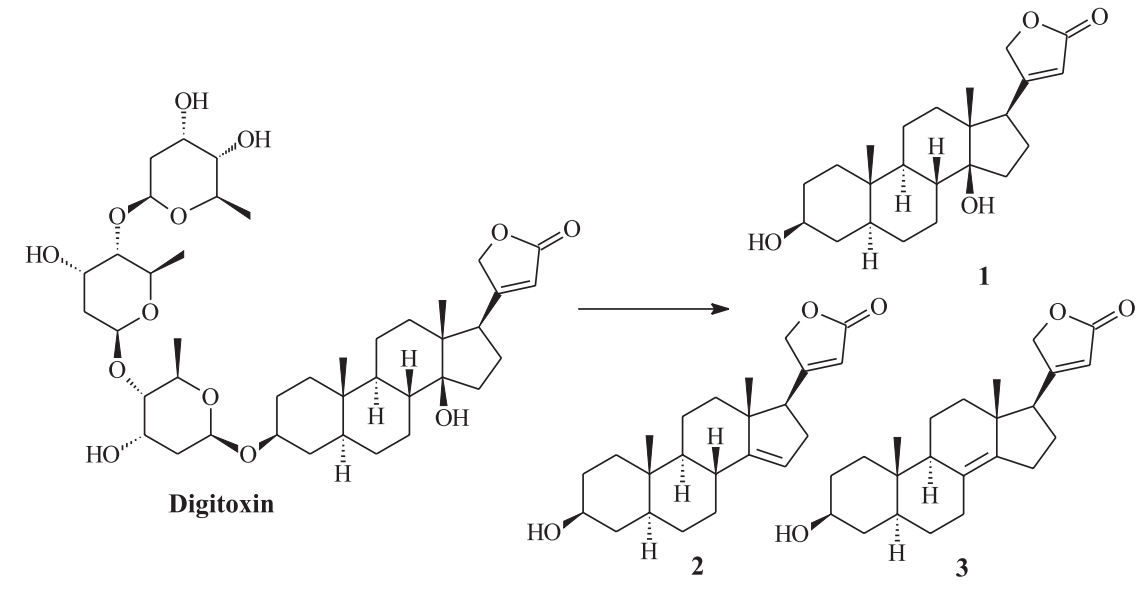

Figure 2. Production of digitoxigenin (1) by the acid hydrolysis of digitoxin. 
Erlenmeyer flasks (300 mL) containing $100 \mathrm{~mL}$ of sterile medium (composition: $2.0 \%$ glucose, $0.5 \%$ peptone, $0.3 \%$ yeast extract and $0.3 \% \mathrm{KH}_{2} \mathrm{PO}_{4}, \mathrm{pH}$ adjusted to 5.7) were inoculated with fresh fungal suspension. Digitoxigenin (1) $(10 \mathrm{mg})$ was dissolved in DMF $(1 \mathrm{~mL})$ and added to the flasks, following incubation at room temperature $\left(24-26^{\circ} \mathrm{C}\right)$, under stirring $(200 \mathrm{rpm})$ for 5 days. The total amount of digitoxigenin (1) submitted to biotransformation was $60 \mathrm{mg}$. Control experiments containing medium plus substrate (C-1) and medium plus fungus culture (C-2) were carried out in each case. After removing the mycelium by filtration, the biotransformation products were sequentially extracted with chloroform $(2 \times 100 \mathrm{~mL})$ and chloroform/ isopropanol $(3: 1)(100 \mathrm{~mL})$ in a separator funnel and the solvent was vacuum removed at $50{ }^{\circ} \mathrm{C}$, until residue. The obtained residues were combined $(138.6 \mathrm{mg}$ ) and submitted to purification by preparative RP-HPLC, under the conditions described for digitoxigenin purification. Elution was performed with $84 \%$ aqueous $\mathrm{CH}_{3} \mathrm{CN} / \mathrm{H}_{2} \mathrm{O}$ in different compositions: 37:63 for the isolation of compounds 4 $\left(\mathrm{t}_{\mathrm{R}}: 19.4 \mathrm{~min}, 10.3 \mathrm{mg}, 16 \%\right.$ yield $)$ and $\mathbf{5}\left(\mathrm{t}_{\mathrm{R}}: 24.9 \mathrm{~min}, 9.8\right.$ $\mathrm{mg}, 16 \%$ yield), and $1: 1$ for product $6\left(\mathrm{t}_{\mathrm{R}}: 46.9 \mathrm{~min}, 4.7 \mathrm{mg}\right.$, $8 \%$ yield).

The biotransformation of digitoxin (10 mg/flask) was carried out in the conditions described for digitoxigenin (1). The reaction was stopped after 11 days and the products were immediately extracted as previously described. The biotransformation of digitoxin in the presence of digitoxigenin ( $8 \mathrm{mg}$ and $2 \mathrm{mg} / \mathrm{flask}$, respectively) was also performed. In one of the experiments, the flasks were submitted to sonication for $30 \mathrm{~min}$, prior to incubation, whereas in the other, $0.15 \% \mathrm{~m} / \mathrm{m}$ Tween 80 was added to the reaction medium.

\section{Kinetics of digitoxigenin biotransformation}

The biotransformation conditions were those previously described. The reaction was monitored by removing portions $(2.7 \mathrm{~mL})$ of the culture medium with a syringe, at regular intervals $(36,60,84,108,132$ and $156 \mathrm{~h})$ and the cardenolides were analyzed by RP-HPLC, after appropriate extraction. HPLC analysis were carried out in a MerckHitachi apparatus (Germany) composed of intelligent pump L-6200A, autosampler AS-2000A, UV-VIS detector L-4250 and integrator D-2500. An ODS column $(250 \times 4.0 \mathrm{~mm}$ I.D., $5 \mu \mathrm{m}$ ) was employed (Merck, Germany) with temperature of $40{ }^{\circ} \mathrm{C}$, flow rate of $1.0 \mathrm{~mL} \mathrm{~min}{ }^{-1}$ and wave length of $220 \mathrm{~nm}$. A gradient elution of $\mathrm{H}_{2} \mathrm{O}(\mathrm{A})$ and $84 \%$ aqueous $\mathrm{CH}_{3} \mathrm{CN}$ (B) was performed: $0 \mathrm{~min} 76 \% \mathrm{~A}, 24 \% \mathrm{~B} ; 16.5 \mathrm{~min}$ $58 \%$ A, $42 \%$ B; $22.5 \min 52 \%$ A, $48 \%$ B; $30 \min 28 \%$ A, $72 \% \mathrm{~B} ; 35 \mathrm{~min} 11 \% \mathrm{~A}, 89 \% \mathrm{~B}$. The identification of the components was accomplished by comparing the retention time of the products with those of the isolated cardenolides, injected in the same conditions.

\section{Results and Discussion}

Digitoxigenin (1), employed as substrate for biotransformation in the present work, was obtained by the acid hydrolysis of digitoxin under previously described conditions, ${ }^{8}$ with some modifications (Figure 2 ). The temperature of the hydrolysis reaction was held at $55{ }^{\circ} \mathrm{C}$, for $35 \mathrm{~min}$, to minimize the formation of the side product digitoxigenin-monodigitoxoside. After isolation and purification of the obtained digitoxigenin (1) by preparative RP-HPLC, its purity and authenticity was attested by NMR analysis and by data comparison with authentic samples (Table 1).

Besides digitoxigenin (1) (80\%), two other products were obtained from the hydrolysis of digitoxin, resulting from dehydration of the hydroxyl group at C-14 (Figure 2). Proton chemical shifts of compound 2 were generally consistent with those of digitoxigenin (1), the major

Table 1. ${ }^{1} \mathrm{H}$ NMR assignments of digitoxigenin (1), its dehydration derivatives $(\mathbf{2}, \mathbf{3})$ and biotransformation products $(\mathbf{4}, \mathbf{5}, \mathbf{6})$ by Fusarium ciliatum

\begin{tabular}{|c|c|c|c|c|c|c|}
\hline \multirow[b]{2}{*}{ Hydrogen } & \multirow[b]{2}{*}{1} & \multicolumn{4}{|c|}{ Chemical shifts $[\delta(p p m)]$} & \multirow[b]{2}{*}{6} \\
\hline & & 2 & 3 & 4 & 5 & \\
\hline $1 \alpha$ & 1.49 & 1.49 & 1.53 & 1.49 & 2.11 & 1.59 \\
\hline $1 \beta$ & 1.49 & 1.49 & 1.53 & 1.49 & 1.45 & 1.46 \\
\hline $2 \alpha$ & 1.53 & 1.49 & 1.61 & 1.53 & 2.53 & 2.34 \\
\hline $2 \beta$ & 1.53 & 1.49 & 1.61 & 1.53 & 2.11 & 2.21 \\
\hline $3 \alpha$ & 4.13 & 4.11 & 4.17 & 4.14 & - & - \\
\hline $4 \alpha$ & 1.34 & 1.35 & 1.42 & 1.39 & 2.78 & 2.62 \\
\hline $4 \beta$ & 1.89 & 1.94 & 2.07 & 1.94 & 1.95 & 2.13 \\
\hline $5 \beta$ & 1.78 & 1.78 & 1.84 & 1.84 & 1.81 & 1.84 \\
\hline $6 \alpha$ & 1.87 & 1.97 & 1.89 & 1.90 & 1.93 & 1.86 \\
\hline $6 \beta$ & 1.30 & 1.29 & 1.25 & 1.32 & 1.34 & 1.44 \\
\hline $7 \alpha$ & 1.25 & 1.30 & 1.90 & 1.26 & 1.31 & 1.36 \\
\hline $7 \beta$ & 1.71 & 1.60 & 2.18 & 1.71 & 1.84 & 1.82 \\
\hline $8 \beta$ & 1.56 & 2.06 & - & 1.54 & 1.66 & 1.63 \\
\hline $9 \alpha$ & 1.62 & 2.06 & 2.38 & 1.66 & 1.91 & 1.76 \\
\hline $11 \alpha$ & 1.46 & 1.68 & 1.60 & 1.68 & 1.65 & 1.52 \\
\hline $11 \beta$ & 1.46 & 1.44 & 1.50 & 1.27 & 1.34 & 1.32 \\
\hline $12 \alpha$ & 1.40 & 1.39 & 1.24 & 3.38 & 3.47 & 1.47 \\
\hline $12 \beta$ & 1.53 & 1.90 & 1.74 & - & - & 2.03 \\
\hline $15 \alpha$ & 2.13 & 5.23 & 2.43 & 1.89 & 2.07 & 2.15 \\
\hline $15 \beta$ & 1.71 & - & 1.95 & 1.82 & 1.77 & 1.73 \\
\hline $16 \alpha$ & 1.87 & 2.45 & 1.92 & 1.97 & 1.95 & 1.92 \\
\hline $16 \beta$ & 2.16 & 2.45 & 2.31 & 2.16 & 2.15 & 2.18 \\
\hline $17 \alpha$ & 2.79 & 2.79 & 2.34 & 3.33 & 3.35 & 2.80 \\
\hline 18 & 0.88 & 0.81 & 0.80 & 0.81 & 0.82 & 0.91 \\
\hline 19 & 0.96 & 0.98 & 0.85 & 0.97 & 1.05 & 1.03 \\
\hline $21 \mathrm{a}$ & 5.00 & 4.81 & 4.84 & 4.90 & 4.99 & 4.99 \\
\hline $21 b$ & 4.81 & 4.71 & 4.71 & 4.81 & 4.91 & 4.81 \\
\hline 22 & 5.87 & 5.89 & 5.87 & 5,94 & 5,99 & 5,90 \\
\hline
\end{tabular}

Samples 1, 2, 3 and 6 were dissolved in $\mathrm{CDCl}_{3} ; 4$ and 5 in $\mathrm{CD}_{3} \mathrm{OD}$. 
Table 2. ${ }^{13} \mathrm{C}$ NMR assignments of digitoxigenin (1), its dehydration derivatives $(\mathbf{2}, \mathbf{3})$ and biotransformation products $(\mathbf{4}, \mathbf{5}, \mathbf{6})$ by Fusarium ciliatum

\begin{tabular}{|c|c|c|c|c|c|c|}
\hline \multirow[b]{2}{*}{ Carbom } & \multicolumn{6}{|c|}{ Chemical shifts $[\delta(p p m)]$} \\
\hline & 1 & 2 & 3 & 4 & 5 & 6 \\
\hline 1 & 29.6 & 29.7 & 29.4 & 29.6 & 37.8 & 39.8 \\
\hline 2 & 27.9 & 27.9 & 28.3 & 27.9 & 37.9 & 37.1 \\
\hline 3 & 66.8 & 66.8 & 66.9 & 66.7 & 215.7 & 212.3 \\
\hline 4 & 33.3 & 33.2 & 33.2 & 33.3 & 43.0 & 42.1 \\
\hline 5 & $36.0^{\mathrm{b}}$ & $36.2^{\mathrm{b}}$ & $36.6^{\mathrm{b}}$ & 36.0 & 45.4 & 43.6 \\
\hline 6 & 26.5 & 26.1 & 26.8 & 26.3 & 27.8 & 26.5 \\
\hline 7 & $21.2^{\mathrm{c}}$ & $21.8^{\mathrm{c}}$ & $24.7^{\mathrm{c}}$ & 21.6 & 22.4 & 21.0 \\
\hline 8 & 41.8 & 39.6 & $129.7^{\mathrm{e}}$ & 41.4 & 42.1 & 41.7 \\
\hline 9 & $35.5^{\mathrm{b}}$ & $35.3^{\mathrm{b}}$ & $35.5^{\mathrm{b}}$ & 32.4 & 34.3 & 36.7 \\
\hline 10 & 35.4 & 35.3 & 37.0 & 35.2 & 36.3 & 35.2 \\
\hline 11 & $21.3^{c}$ & $23.9^{c}$ & $19.6^{\mathrm{c}}$ & 30.4 & 30.8 & 21.2 \\
\hline 12 & 40.0 & 41.5 & 36.1 & 75.1 & 75.4 & 36.7 \\
\hline 13 & 49.6 & 48.7 & 43.7 & 55.5 & 57.3 & 49.6 \\
\hline 14 & 85.5 & 154.3 & $138.3^{\mathrm{e}}$ & 85.9 & 86.6 & 85.3 \\
\hline 15 & 33.1 & 116.5 & 25.8 & 33.2 & 33.5 & 33.2 \\
\hline 16 & 26.9 & 33.6 & 25.9 & 27.4 & 28.4 & 26.9 \\
\hline 17 & 51.0 & 52.8 & 51.8 & 45.6 & 47.0 & 50.8 \\
\hline 18 & 15.7 & 18.3 & 19.3 & 8.9 & 9.9 & 15.8 \\
\hline 19 & 23.7 & 23.5 & 24.1 & 23.6 & 22.8 & 22.5 \\
\hline 20 & $174.5^{\mathrm{d}}$ & $170.6^{\mathrm{d}}$ & $170.6^{\mathrm{d}}$ & $174.2^{\mathrm{a}}$ & $177.3^{\mathrm{a}}$ & $174.1^{\mathrm{a}}$ \\
\hline 21 & 73.4 & 73.5 & 73.5 & 73.6 & 75.4 & 73.4 \\
\hline 22 & 117.6 & 116.3 & 116.5 & 117.8 & 117.8 & 117.9 \\
\hline 23 & $174.4^{\mathrm{d}}$ & $173.9^{\mathrm{d}}$ & $173.9^{d}$ & $174.5^{\mathrm{a}}$ & $178.4^{\mathrm{a}}$ & $174.3^{\mathrm{a}}$ \\
\hline
\end{tabular}

Samples 1, 2, 3 and 6 were dissolved in $\mathrm{CDCl}_{3} ; 4$ and 5 in $\mathrm{CD}_{3} \mathrm{OD}$. ${ }^{\mathrm{a}-\mathrm{f}}$ Values may be interchangeable.

difference being the resonance of an olefinic proton at $\delta$ $5.23(J 2.3 \mathrm{~Hz}, 1 \mathrm{H}, d)$ assigned to $\mathrm{H}-15 \alpha$. COSY spectroscopy allowed establishing correlations between H-17 $\alpha$ and H-16 protons ( $\delta$ 2.45) which, in turn, showed cross peaks with $\mathrm{H}-15 \alpha$. Moreover, paramagnetic shifting of C-14 and C-15 signals, observed for digitoxigenin (1) at $\delta 85.5$ and $\delta 33.1$ to $\delta 154.0$ and $\delta 116.5$, respectively, allowed the unambiguous assignment of product $\mathbf{2}$ as $\Delta^{14-15}$-digitoxigenin.

In a similar way, ${ }^{13} \mathrm{C}$ NMR spectrum of product 3 revealed the signals of two olefinic non-hydrogenated carbons at $\delta 129.7$ and $\delta 138.3$, respectively assigned to C-8 and C-14, which allowed identifying the other dehydration derivative as $\Delta^{8-14}$-digitoxigenin $(\mathbf{3})$.
Excepting the diamagnetic shifting observed for $\mathrm{H}-7 \alpha(\delta$ $1.90), \mathrm{H}-7 \beta(\delta 2.18)$ and $\mathrm{H}-9 \alpha(\delta 2.38)$, credited to the vicinity of the double bond, all the other chemical shifts were in agreement with those observed for digitoxigenin (1). Hence, these data allowed the unequivocal identification of compound $\mathbf{3}$ as $\Delta^{8-14}$-digitoxigenin.

Three compounds were isolated from the biotransformation of digitoxigenin by Fusarium ciliatum (Figure 3). Structure elucidation was accomplished by 1D and 2D NMR techniques, using digitoxigenin (1) as model compound and also by comparison with spectral data reported for other cardenolides.

The ${ }^{1} \mathrm{H}$ NMR spectrum of compound 4 showed a complex profile and the only signals easily assigned were those of $\mathrm{H}-3(\delta 4.14), \mathrm{H}-21(\delta 4.90$ and $\delta 4.81)$ and $\mathrm{H}-22(\delta$ 5.94), which confirmed the presence of the hydroxyl group at C-3 and the $\alpha, \beta$ unsaturated lactone ring. Besides, the singlets at $\delta 0.81$ and $\delta 0.97$ were readily assigned to the methyl groups at $\mathrm{C}-18$ and $\mathrm{C}-19$. The signal at $\delta 3.4(\mathrm{~J}$ $11.0 \mathrm{~Hz}$ and $6.4 \mathrm{~Hz}, 1 \mathrm{H}$, dd) was assigned to a methine hydrogen bearing a hydroxyl group, thus indicating a hydroxylated derivative.

The hydroxylation position was defined on the basis of the chemical shift changes observed for compound $\mathbf{4}$ in comparison to digitoxigenin (1). Hence, the resonances of C-18 $(\delta 8.9), \mathrm{H}-18(\delta 0.81)$ and $\mathrm{H}-11 \beta(\delta 1.27)$ exhibited diamagnetic shifts in comparison to those registered for digitoxigenin (1) ( $\delta$ 15.7, $\delta 0.88$ and $\delta 1.46$, respectively), allowing to locate the hydroxyl group at the $12 \beta$ position. These shifts were rationalized as resulting from anisotropic effects of the C-23 carbonyl group and the C-20/22 double bond which, in turn, are the outcome of conformational changes of the steroidal frame or the $\alpha, \beta$-unsaturated lactone ring. These data led to the unambiguous identification of $\mathbf{4}$ as digoxigenin.

Similarly to digoxigenin (4), the ${ }^{1} \mathrm{H}$ NMR spectrum of 5 showed a signal at $\delta 3.47(J 11.8 \mathrm{~Hz}$ and $4.2 \mathrm{~Hz}, 1 \mathrm{H}$, dd $)$ attributed to a hydroxylated methine group. Likewise $\mathbf{4}$, the hydroxylation site of compound $\mathbf{5}$ was deduced from the paramagnetic shifting of the signals from $\mathrm{H}-18, \mathrm{C}-18$

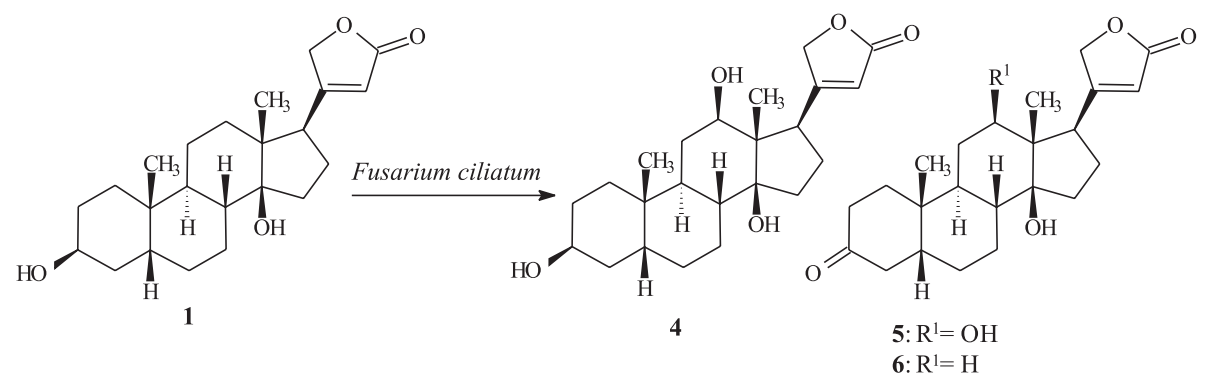

Figure 3. Biotransformation reaction of digitoxigenin (1) by Fusarium ciliatum: production of digoxigenin (4), digoxigenone (5) and digitoxigenone $(\mathbf{6})$. 
and $\mathrm{H}-11 \beta$, which indicated a $12 \beta$-hydroxylated derivative. Another feature of the ${ }^{1} \mathrm{H}$ NMR spectrum of $\mathbf{5}$ was the absence of the characteristic $\mathrm{H}-3 \alpha$ signal at $c a . \delta$ 4.10 in the spectra of $\mathbf{1}$ and $\mathbf{4}$, which pointed out the oxidation of the $\mathrm{C}-3 \beta \mathrm{OH}$. This was confirmed by the chemical shifts observed for $\mathrm{H}-2 \alpha(\delta 2.53), \mathrm{H}-2 \beta(\delta 2.11)$, $\mathrm{H}-4 \alpha(\delta 2.78)$ and $\mathrm{H}-4 \beta(\delta 1.95)$, within the range expected for $\alpha$-carbonyl protons, ${ }^{9}$ as well as by the carbonyl resonance at $\delta 215.7$, revealed by the ${ }^{13} \mathrm{C}$ NMR spectrum. Excepting these signals, the other resonances registered for 5 were in agreement with those obtained for digitoxigenin (1) and confirmed the integrity of the cardenolide skeleton. Based on these findings the structure of $\mathbf{5}$ was assured as digoxigenone.

The carbon-13 and proton chemical shifts observed for compound $\mathbf{6}$ were generally consistent with those of digitoxigenin (1), excepting the absence of the $\mathrm{H}-3 \alpha$ resonance signal, likewise $\mathbf{5}$, which indicated the oxidation of the $\mathrm{C}-3 \beta \mathrm{OH}$. This was confirmed by the paramagnetic shifts of the resonances from $\mathrm{H}-2 \alpha(\delta 2.34), \mathrm{H}-2 \beta(\delta 2.21)$, $\mathrm{H}-4 \alpha(\delta 2.62)$ and $\mathrm{H}-4 \beta(\delta 2.13)$, as a consequence of the vicinity of the C-3 carbonyl. The assignment of C-1 $(\delta$ 39.8) was accomplished by a HMQC experiment, which disclosed cross peaks with $\mathrm{H}-1 \alpha(\delta 1.59)$ and $\mathrm{H}-1 \beta(\delta 1.46)$, whereas the correlation of these hydrogens with $\mathrm{H}-2 \beta$ ( $\delta$ 2.34) was revealed by COSY spectroscopy. The oxidation of the $\mathrm{C}-3 \beta \mathrm{OH}$ was also evidenced by the carbonyl signal at $\delta 212.3$ in the ${ }^{13} \mathrm{C}$ NMR spectrum, allowing the unambiguous identification of $\mathbf{6}$ as digitoxigenone.

The biotransformation of digitoxigenin (1) by $F$. ciliatum has been previously carried out on a 11 days process and afforded $100 \%$ yield of digoxigenone (5). ${ }^{6,7}$ In the present work, shortening of the biotransformation reaction time to 5 days afforded the products digoxigenin (4), digoxigenone (5) and digitoxigenone (6) (Figure 3). In order to explain these results, we decided to investigate the biotransformation kinetics of the reaction. Monitoring of the incubation medium by HPLC analysis disclosed digitoxigenone (6) as the first product to be formed (Figure 4), followed by the more polar hydroxylated compounds digoxigenin (4) and digoxigenone (5), that were detected after 24 hours (Figure 5). These data suggest the involvement of different enzymes in the $12 \beta$ hydroxylation and C-3 oxydation of digitoxigenin (1). After 156 hours, the consumption of the substrate digitoxigenin (1) was almost complete, resulting in the formation of digoxigenin (4). In addition, hydroxylation of the first formed product digitoxigenone (6) occurred in a great extension, leading to the production of digoxigenone (5). Although we did not detect the transformation of compound $\mathbf{4}$ into $\mathbf{5}$, in our 5 days process, digoxigenone (5) seems to be the final transformation product of digitoxigenin (1) by F. ciliatum, once it has been previously obtained in a $100 \%$ yield, employing a 11 days process. ${ }^{6,7}$

A triangular hydroxylation model has been proposed for the biotransformation of 5-androstanes by F. ciliatum (syn. Calonectria decora) wherein one of the triangle vertices is the electron rich group and the two others are the sites for hydroxylation. ${ }^{10-13}$ The 5-androstanes evaluated in those studies possess a hydroxyl or a carbonyl group at $\mathrm{C}-3$ and as a result $\mathrm{C}-12$ and $\mathrm{C}-15$ hydroxylated derivatives were obtained. According to the model,
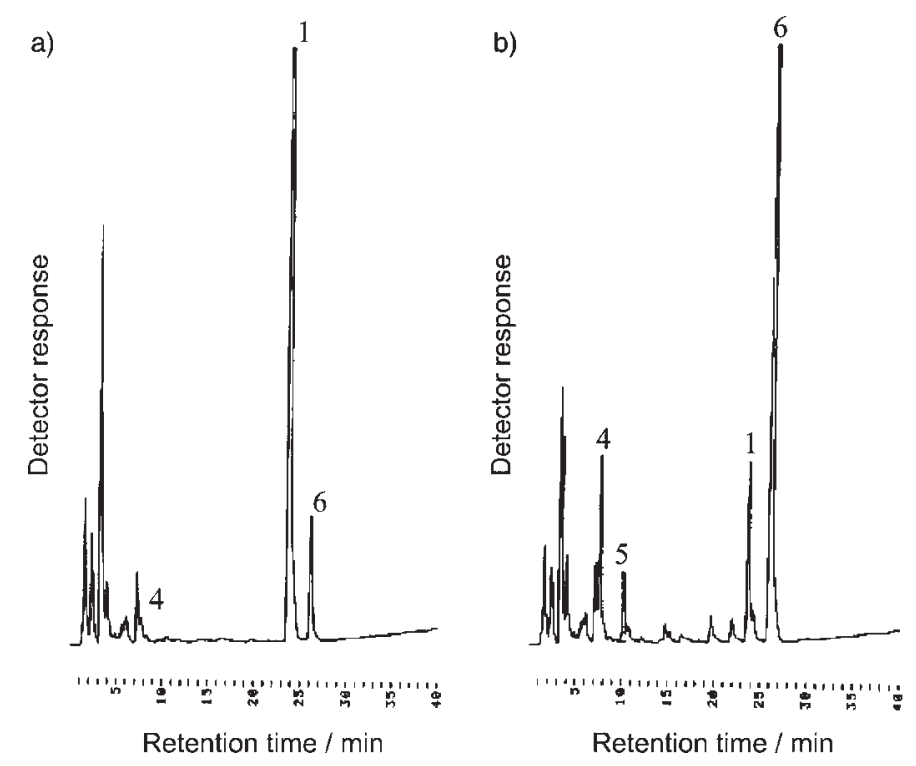

c)

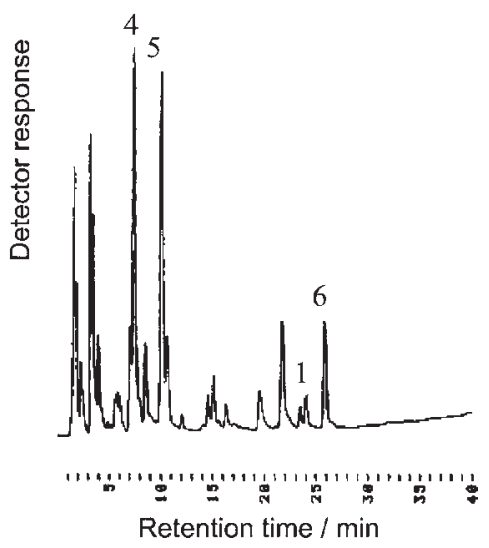

Figure 4. RP-HPLC chromatograms obtained for the biotransformation of digitoxigenin (1) by Fusarium ciliatum after (a) 60 hours, (b) 108 hours and (c) 156 hours of reaction. Chromatographic conditions: see experimental. $\mathbf{1}=$ digitoxigenin; $\mathbf{4}=\operatorname{digoxigenin} ; \mathbf{5}=$ digoxigenone; $\mathbf{6}$ $=$ digitoxigenone. 


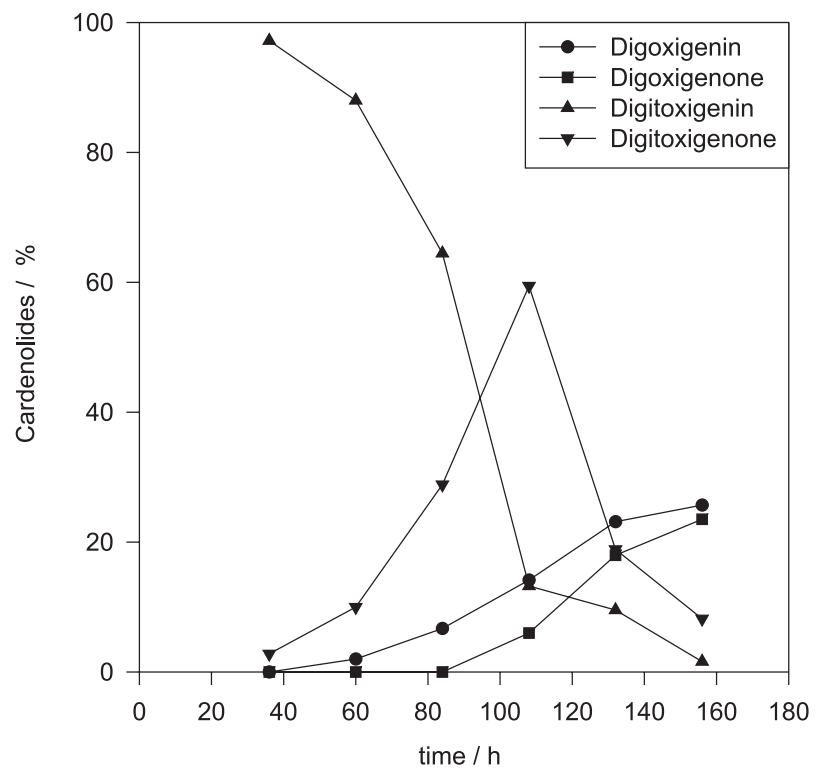

Figure 5. Biotransformation kinetics of digitoxigenin (1) by Fusarium ciliatum. Cardenolides percentile content was estimated by normalization of peak areas from RP-HPLC chromatograms.

changes on the steroid geometry results in alteration of the hydroxylation sites. In the present work, however, this rule was not strictly followed by digitoxigenin (1), a $5 \beta$ steroid, since we have obtained the $12 \beta$ hydroxylated products digoxigenin (4) and digoxigenone (5). On the other hand, no $\mathrm{C} 15-\mathrm{OH}$ derivative nor $\mathrm{C}-12 / \mathrm{C}-15$ dihydroxylated product was obtained from digitoxigenin (1). These findings were rationalized as being due to the location of the C-14 hydroxyl group in the cardenolide ring, once the presence of an electron rich group near to the hydroxylation site is known to inhibit the reaction. ${ }^{13}$ Therefore, both the changes on the steroid geometry and the presence of the hydroxyl group could explain the absence of a C-15 hydroxylated product.

Despite the good results obtained with digitoxigenin (1), F. ciliatum has been unable to promote hydroxylation of digitoxin (Figure 1) under the tested conditions. The $12 \beta$ hydroxylation of this cardenolide has been previously accomplished with Digitalis cell cultures. ${ }^{14}$ Our negative result may be attributed to the low solubility of digitoxin in the reaction medium. In order to improve the solubility, we tried the micronization of digitoxin by sonication and the addition of $0.15 \% \mathrm{~m} / \mathrm{m}$ Tween 80 to the reaction medium. Both strategies, however, did not result in the recovery of any biotransformation product of digitoxin. These experiments were carried out with mixtures of digitoxin and digitoxigenin (1) in the same flask and resulted in digoxigenin as the only biotransformation product, which allowed us to assure the integrity of the fungus enzymatic system. Another hypothesis to explain the negative result with digitoxin would be the greater permeability of vegetal cell membranes in comparison to fungus cells. The use of chemicals such as cyclodextrines to improve the permeability of digitoxin through the fungus membrane may represent an alternative to overcome this problem and will be assayed in the future.

\section{Conclusions}

The present work has demonstrated the viability of converting digitoxigenin (1) into digoxigenin (4) in a 5 days fermentation process with $F$. ciliatum. The appropriate conditions for the $12 \beta$ hydroxylation of digitoxin might be further investigated aiming at the production of the therapeutically important digoxin.

\section{Acknowledgements}

This research was supported by grant CDS1203/98 from FAPEMIG (Brazil). CNPq (Brazil) is also acknowledged for research fellowships (F.C.B) and for a graduate fellowship (R.M.P.).

\section{References}

1. Kreis, W.; Hensel, A.; Stuhlemmer, U.; Planta Med. 1998, 64, 491.

2. Kreis, W.; Reinhard, E.; J. Biotechnology 1992, 26, 257.

3. Giri, A.; Dhingra, V.; Giri, C. C.; Singh, A.; Ward, O .P.; Narusu, M. L.; Biotechnology Adv. 2001, 19, 175.

4. Tamm, C.; Gluber, A.; Helv. Chim. Acta 1958, 41, 239.

5. Gluber, A.; Tamm, C.; Helv. Chim. Acta 1958, 41, 297

6. Nozaki, Y.; Agricultural Biol. Chem. 1961, 25, 461.

7. Nozaki, Y.; Agricultural Biol. Chem. 1961, 25, 890.

8. Haussman, W.; Kreis, W.; Stuhlemmer, U.; Reinhard, E.; Planta Med. 1997, 63, 446.

9. Bhacca, N. S.; Willians, D. H.; Applications of NMR Spectroscopy in Organic Chemistry: Illustrations from the Steroid Field, Holden-Day: San Francisco, 1969.

10. Bell, A. M.; Denny, W. A.; Jones, R. H.; Meakins, G. D.; J. Chem. Soc., Perkin. Trans. 1 1972, 21, 2059.

11. Bell, A. M.; Cherry, P. C.; Clarck, I. M.; Denny, W. A.; Jones, S. E. R. H.; Meakins, G. D.; Woodgate, P. D.; J. Chem. Soc., Perkin. Trans. 1 1972, 16, 2081.

12. Jones, S. R.H.; Meakins, G. D.; Miners, J. O.; Wilkins, A. L.; J. Chem. Soc., Perkin. Trans. 1 1975, 22, 2308.

13. Holland, H. L.; Chem. Soc. Rev. 1982, 11, 371.

14. Kreis, W.; Hoelz, H.; May, U.; Reinhard, E.; Plant Cell, Tissue and Organ Culture 1990, 20, 191.

Received: June 7, 2004 Published on the web: March 21, 2005 